\title{
Aligned Commitment and the High Performance Organisation
}

\section{J G Kotzé}

Potchefstroom Business School, Potchefstroom University for Christian Higher Education

\section{ABSTRACT}

In attempting to achieve high performance levels within the enterprise, the manifestation of aligned commitment is a very desirable goal to aim for. It is instrumental in the realisation of the full potential of organisational members and in focusing their efforts and performance on the strategic vision of the enterprise. A model, which introduces, describes, and integrates the various processes, steps and actions required in the development of aligned commitment, is suggested. Guidelines, derived from research findings as well as experience gained in the actual implementation of the various constituent elements of the model, are supplied. These guidelines should assist in the successful establishment and maintenance of a value-driven, aligned commitment culture within any enterprise.

JEL J20, J50, L20, M12

\section{INTRODUCTION}

The evolving business environment of the $21^{\text {st }}$ century is making new and unique demands on the modern manager and leader. Today's executive needs to be competent in leadership, which is defined as "influencing and directing the behaviour of individuals and groups in such a way that they work willingly to pursuc the objectives of the organisation" (Smit \& Cronje, 2000: 279). Those business leaders who are not successful in this regard, "risk being overwhelmed by factors such as burcaucratic infighting, narrow-minded politics, destructive power struggles, and the like which regularly reduce initiative, innovation, morale and excellence in the organisation" (Kotter, 1985: 3). The influencing and directing of the performance of subordinates (team members) to the pursuance of organisational objectives has become known as commitment (Meyer \& Allen, 1997: 12; Kreitner \& Kinicki, 1995: 162; Mowday, et al., 1982: 27) or as aligned commitment (Kotzé, 2001: 11; Coetsee, 1996: 23). 
In the last three decades, the construct of aligned commitment has been thoroughly researched. This research has yielded several definitions of aligned commitment (Sheldon, 1971: 143; Hall, Schneider \& Nygren, 1970: 176; in Meyer \& Allen, 1997: 12; Mowday, et al., 1982: 27; Kreitner \& Kinicki, 1995; Wiener, 1982: 421). These definitions identify and stress different aspects of aligned commitment. The majority of the distinguishable facets of commitment contained in the definitions are reflected in the definition of commitment formulated by Mowday, et al. (1997: 235): "An employee's belief in and acceptance of the values and beliefs of the organisation, coupled with the willingness to exert considerable effort on behalf of the organisation, and a strong desire to maintain membership therein".

\section{ALIGNED COMMITMENT AND PERFORMANCE}

Meyer \& Allen (1997: 67) have identified and defined three broad components of commitment namely; affective, continuance, and normative commitment. These components are all, to a certain degree, reflected in the Mowday definition above. Affective commitment is the employee's emotional attachment to, identification with and involvement in the organisation or group. Employees with a strong affective commitment continue membership because they want to do so. The same authors (1997: 30) have pointed out that the definition of affective commitment is clearly based on the values of the employee being congruent with that of the organisation.

Continuance commitment refers to an awareness of the costs associated with discontinuing the relationship with the organisation. Employees whose primary link to the organisation is based on continuance commitment, remain because they need to do so.

Normative commitment reflects a feeling of obligation to continue the relationship. Employees with a high level of normative commitment feel that they ought to remain with the organisation.

Normative commitment has been shown to be the weakest of the three dimensions, while affective commitment has proven to be the strongest dimension (Meyer \& Allen, 1997: 28-35; Mowday, et al., 192: 15; Myers \& Miller, 1997: 17). The two stronger dimensions of commitment have been shown to relate to different organisational consequences. Continuance commitment has been linked to general decreases in employee turnover as people cannot afford to leave their organisation, but has not been linked with any aspect of performance (Angle \& Perry, 1981; Hom, Katerberg \& Hulin, 1979; Porter, $t$ al., 1976; Werbel \& Gould, 1984 in Angle and Lawson, 1994: 1540). Research 
evidence for an aligned commitment-performance link, has been rare. Where such a linkage has been found, it has related only to affective commitment. Meyer, et al. (1989) in Angle \& Lawson, (1994: 1541) found a positive link with job performance for affective commitment, but not for continuance commitment. An interesting conclusion following exhaustive research in a Fortune 500 company by Angle \& Lawson (1994: 1544) was that affective commitment was positively related to two of the four performance facets measured, namely dependability and initiative, but was unrelated to accomplishment or judgement. This supports the intuitive perception that performance is inevitably a multidimensional manifestation. Furthermore, this multidimensional performance is the product of both ability, as well as motivation (Mullins, 1996: 444).

The definition of affective commitment stresses its motivational nature. This implies that the linkage between performance and affective commitment is predicated upon the latter's effect on team members' willingness to exert additional effort (Porter, et al., 1976; Angle \& Lawson, 1994: 1547). These researchers found no implied relationship between affective commitment and ability. Angle \& Lawson (1994: 1547-48) conclude that the positive relationship between affective commitment and dependability and initiative can be explained by the reasonable assumption that these two performance facets rely more on effort and motivation and less on ability. The two unrelated performance aspects of judgement and accomplishment are more dependent on ability than on motivation and, consequently, on effort.

A general conclusion from prior research into aligned commitment and performance therefore, is that the following desirable organisational consequences can be obtained from a committed workforce: A decrease in turnover, an increase in motivation and effort, decreased absenteeism, greater initiative and dependability and job satisfaction (Myers \& Miller, 1997: 15; Bateman \& Stasser, 1984; Mowday, Porter and Steers, 1982; Mowday, Porter and Steers, 1979; Mathieu \& Jujac, 1990; Clegg, 1983; Cotton \& Tuttle, 1986 in Becker, Billings, Eveleth \& Gilbert, 1996: 464). The latter researchers also found that overall aligned commitment to direct supervisors (superiors) is positively related to job performance and is more strongly linked to performance than overall commitment to the organisation itself (Becker, Billings, Eveleth \& Gilbert, 1996: 467).

The three implications for a proposed model of aligned commitment to elicit high overall performance in the organisation, are the following:

The importance of shared values as one of the elements required for aligned commitment; 
- Ability (competencies) should receive as much attention in the model as effort (motivation) does;

- The relationship on all organisational levels between superior and immediate subordinates is of critical significance in developing aligned commitment in the enterprise.

\section{A MODEL TO FACILITATE ALIGNED COMMITMENT}

The following model (Figure 1) is suggested as an integrated guideline to facilitate aligned commitment and to achieve high, overall performance levels in the enterprise. This model is derived from the Kotze (2001: 11) model of aligned commitment in strategy implementation, the Coetsee (1996: 112) model for the creation of a motivating climate, and the Kreitner \& Kinicki (1995: 142) job performance model of motivation. Each element of the model will now be discussed and integrated with the other elements.

\section{- The Strategic Plan}

The achievement of aligned commitment and high performance, like all other desirable business outcomes, starts with an "appropriate" and "winning" strategy. Appropriate business strategies are well suited to the future demands and characteristics of the macro, as well as the operating environment of the enterprise; they contribute to sustainable competitive advantage and lead to superior financial results.

Winning business strategies emphasise the critical importance of knowledge and intellectual capital (competencies), the flexibility of business processes and systems, the continuous reinvention by means of innovation and creativity, a culture of strategic thinking and organisational learning and the essential ability to manage time effectively (Kotzé, 2001: 3-4).

During the formulation of appropriate and winning strategies, three additional elements of the high performance, aligned commitment model are developed. These elements, namely the objectives, vision statement and the core values are contained within the statement of "organisational purpose". "(S)trategies can engender strong, enduring emotional attachments only when they are embedded in a broader organizational purpose" (Bartlett \& Ghoshal, 1994: 49). This requires the creation of an enterprise with which employees can identify, in which they share a sense of pride and to which they are willing to commit. "In short, senior managers must convert the contractual employees of an economic entity into committed members of a purposeful organization" (Bartlett \& Ghoshal, 1994: 51). 


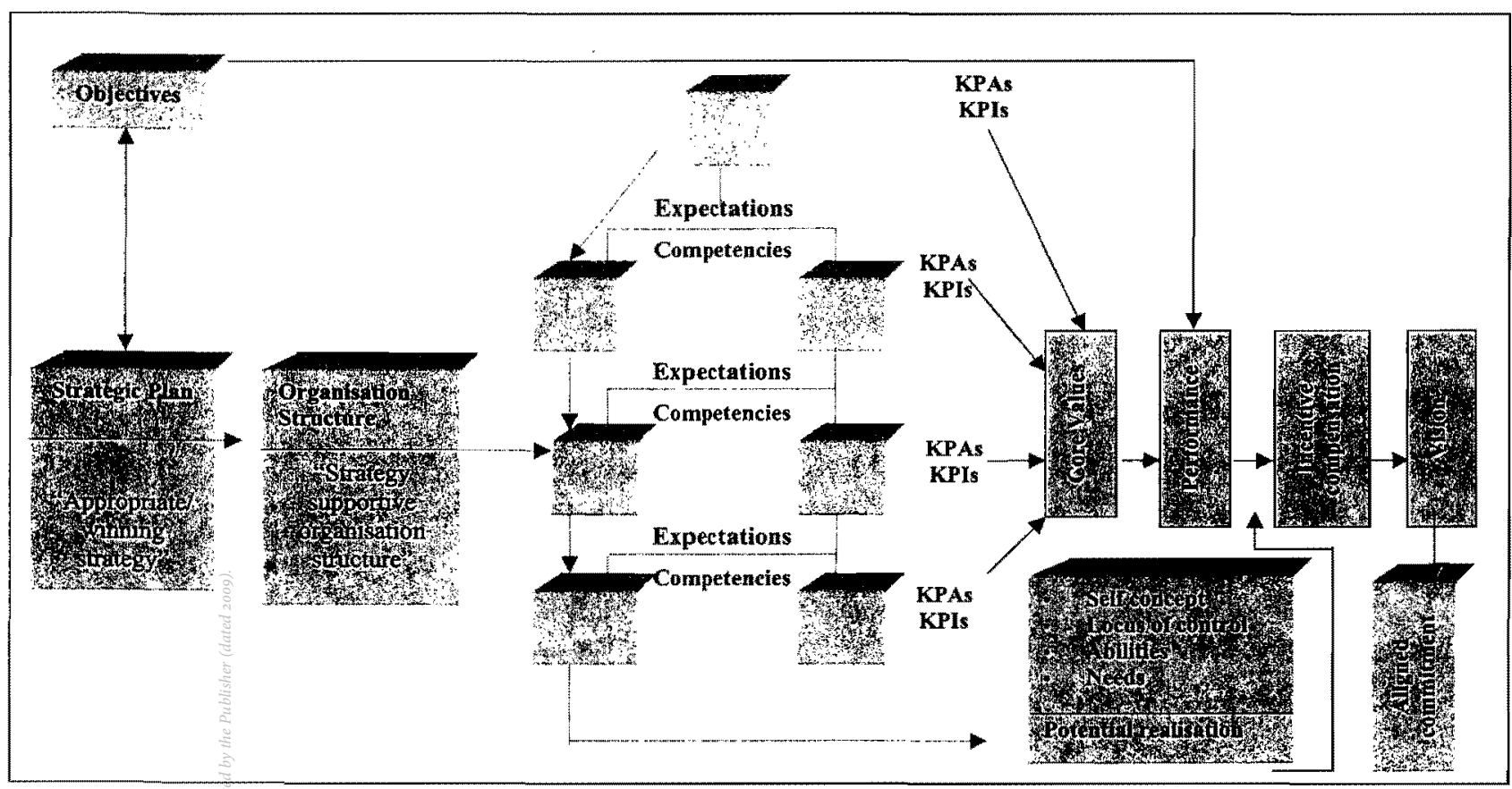

Sources: Kotzé, 2001: 11; Coetsee, 1996: 112; Kreitner \& Kinicki, 1995: 142 
- Objectives

Setting objectives converts the strategic vision into specific performance targets. Objectives represent an organisational and managerial commitment to the achievement of specific outcomes and results. Objectives must be stated in quantifiable (measurable) terms, and they must contain a deadline for achievement. Objectives, along with the vision statement and the core values, are an important part of the statement of organisational purpose of the enterprise. There are few more powerful or public signals of what an enterprise stands for than the way in which it defines and measures performance. A great deal of thought and attention should, accordingly, go into the formulation of appropriate objectives, and the right balance between objective-driven performance and value-driven performance.

The objective-driven performance yields the tangible results required by the strategic plan. This may be described as the "what" of performance. The remaining element consists of the value-driven performance. This may be visualised as the "how" of performance. How was the what attained? Did the employee act in a manner conducive to the overall, long term best interests of the enterprise? Did the employee, in achieving the desired tangible performance result, contribute positively to the image and long-term strategic capacity and potential of the enterprise or did he/she harm these critical aspects? (Kotzé, 2001: 36).

\section{- The Organisation Structure}

Once an appropriate and winning strategy, incorporating vision, core values and objectives, has been formulated, the focus shifts to the conversion of these aspects into actions and high performance. The proficient implementation of the formulated strategy is heavily dependent on:

- An effective, strategy-supportive organisation structure

- Competent people who are:

- Output (results) directed

- Focused on core values

- Empowered

- A leadership/managerial capacity to meet the needs and expectations of the organisation's people, and to realise their full potential.

The organisation structure, as key element of the aligned commitment model, can be described as being effective, and strategy-supportive, if it facilitates the following desirable results (Kotzé, 2001: 109-10): 
- Efficiency

\section{- Effectiveness}

- Strategy support

- Excellent horizontal and vertical communications

- Effective co-ordination of all activities, functions and actions

- Realisation of the full, practically-realisable benefits of the optimum trade-off between centralisation and decentralisation

- Development, protection, maintenance and wide-spread establishment of core competencies within the organisation

- Aligned commitment on all organisational levels.

This organisation structure should be peopled by competent, empowered teams who are continually supported to exercise initiative and to realise their full potential. This requires the effective delegation of sufficient authority to the subordinate to balance the responsibility and accountability the person is expected to accept (Smit \& Cronje, 2000: 281). Managers wishing to unlock the full performance potential of aligned commitment in their organisations, will continually attempt to build the skills and self-confidence of their subordinates (team members). They will delegate authority, share information and allow subordinates to participate in decision-making. These actions tend to optimise the internal motivation, self-control and commitment of team members (Yukl, 1981: 134). These managers will seize every opportunity to empower their team members.

True empowerment requires the superior to furnish those reporting to him/her with the means, ability and accountability to do what is required of them. Without all three, the superior disables, rather than empowers (Schuitema, 2001: 24). Harvey and Brown (1996: 227) define empowerment as "the process of giving employees the power to make decisions about their work" while Beatty \& Ulrich (in Jick, 1993: 71) describe empowerment as "a movement away from leader and expert problem solving to a system where everyone is continually involved in improving the organisation".

High performance and aligned employees in the organisation also need to be output and value focused. In modern performance management processes, the tasks (inputs) performed by individuals and teams are unimportant. Primary concern falls on the results (outputs), normally identified in the form of key performance areas (KPAs) and measured by key performance indicators (KPIs). A KPA is an individual/team result which has high value to the organisation in terms of its strategic plan, as well as the demands placed upon the organisation by the key success factors of the industry in which it operates. The objectives and values of the organisation, already discussed, form the foundation of the formulation of KPAs and KPIs. 
Between every level in this strategy-supportive organisation structure, there are implicit expectations, downwards, as well as upwards. Managers expect certain actions and performance levels from their immediate subordinates; the latter, in turn, expect leadership, guidelines and other inputs from their superiors. These expectations must be made very explicit. They must be identified, classified and communicated. Unrealised expectations usually lead to misunderstandings, grey areas, disillusionment and lack of commitment.

The heart of aligned commitment is to be found between these organisational levels and in the relationship between superior and immediate subordinates. Recall the cited research conclusions that aligned commitment to direct superiors is positively related to job performance and is more strongly linked to performance than overall commitment to the organisation itself. This is amplified by the finding that superior performance is elicited by an effective internalisation of the core values of the superior. It is in this direct organisational relationship that the constituent elements of aligned commitment in the form of strategy, objectives, key performance areas, core values, vision, people's self concepts, their loci of control, their abilities and their needs and expectations come together. If the manager/leader handles all these aspects and the balances between them sensitively, intelligently and patiently, the full benefits of aligned commitment may be realised in the enterprise. It is as if a strong magnet is placed behind the vision block in Figure 1. This magnetic force exerts a pulling power on all the arrows and focuses them on one single future point, namely the compelling destination symbolised by the vision statement.

A misguided handling of these factors may lead to some or all of the following negative consequences over time:

- People lose enthusiasm

- The best people leave the organisation

- Productivity goes down

- Management's credibility suffers

- Most people do not realise their full potential

- Service to clients deteriorates and

- Resistance to change increases exponentially.

-

\section{The Core/Shared Values}

Coetsee (1996: 20) identifies a shared value system which guides the behaviours of employees, as a pre-requisite to aligned commitment. What is required are values that pervade the organisation and that establish the guidelines under which the enterprise's decisions, actions and opinions are framed. The benefit of shared values is that decision-makers have a focus for their decisions, causing 
them to be more consistent. To the extent that values are widely held, the need for complex control mechanisms is lessened (Kotzé, 2001: 15). Desirable values in an organisation are usually derived from the vision statement, as well as the implicit implications of this statement.

O'Reilly \& Chatman (1986: 493) identify three independent bases, for an individual's psychological attachment to an organisation, namely, compliance to stated expectations for specific, extrinsic rewards, identification based on a desire for affiliation and "internalisation predicated on congruence between individual and organizational values". The last (internalisation) basis of commitment links closely with the definition of affective commitment discussed previously. "Having a membership that shares the organizations .... values can ensure that individuals act instinctively to benefit the organization" (Ouchi, 1980; Williamson, 1975; in O'Reilley \& Chatman, 1986: 497).

According to Bartlett \& Ghoshal (1994: 50) it is more difficult to identify, communicate and shape core values than it is to articulate and advocate a strategic vision. They explain this by pointing out that the value establishment process relies less on analysis and logic, and more on emotion and intuition. This effort is, however, very worthwhile, as organisations with clear and boldly asserted core values typically attract and retain employees who identify with organisational values and become more deeply committed to the organisation that embodies these values. Hughes, Ginnet \& Curphy (1999: 286) point out that values play a key role in strategic vision development (as also the latter, in value identification and articulation), and that it also "serves as a moral compass for aligning leaders' and followers' actions with desirable strategic initiatives".

Two examples of widely implemented, desirable strategic initiatives of the $21^{\text {st }}$ century and their attendant values, are the following:

- An intemal locus of control: Values which emphasise the internal locus of control behaviour are those of:

- Responsibility and ownership

- Acceptance of responsibility and exercising of initiative

- Respect for oneself and for others

- Mutual trust

- Creativity and innovation.

A learning organisational climate: Typical core values of leaming organisations include the following:

- Openness or transparency

- Innovation and creativity 
- Acceptance of reasonable risks

- Trustworthiness

- Growth.

From the above, the key role played by the vision and the values in forging strong emotional links and attachments to the organisation and its purpose, is evident. It is again necessary to add the proviso that, in implementing the proposed model of aligned commitment, efforts should be focused on commitment to supervisors rather than on commitment to organisations. An especially strong predictor of superior performance in the organisation appears to be based on "the propensity to become committed to a supervisor (especially a propensity based on internalising the supervisor's values)" (Becker, Billings, Eveleth \& Gilbert, 1996: 468).

In developing, refining and instilling core values, the critical role played by the direct supervisor must be appreciated.

\section{- Incentive Compensation}

The role of compensation in the pursuit of aligned commitment has been thoroughly researched by Lawler (1992 172); Cummings \& Worley (2001 :392); Byars \& Rue (1997: 312). In an organisation with a high level of aligned commitment, a significant portion of the compensation of team members should be dependent on the performance levels of the organisation. The quoted research findings also stress the importance of a creative balance between extrinsic (tangible) rewards and intrinsic (intangible) incentives.

An effective performance based, incentive system can contribute significantly to continuous improvement in team member and work group performance. It can also produce high levels of employee satisfaction.

\section{- The Vision Statement}

The statement of vision is arguably the most important element of the entire aligned commitment model. "Aligned", in the term, refers to the directing (focusing) of the performance outputs of employees on all organisational levels, towards the ultimate realisation of the formulated vision. The vision is accordingly the end result (destination) of the construct of aligned commitment. It is, of course, also the successful end result of the entire process of strategy formulation, as well as implementation.

In a similar vein, "commitment", in the term, refers to the influencing of employee's attitudes towards the organisation and it's vision through the four 
identifiable phases of awareness, support, involvement, and commitment (Coetsee, 1999: 210-213). Again the passionate involvement and organisational citizenship behaviour, known as commitment, is focused on the vision and values of the enterprise. The crucial role played by vision is aptly summarised by Schuitema (2001: 24): "The role of a vision is to provide people with an excuse to suspend their self interest."

A vision can be described as a "desired reality" (Parker, 1990: 2) while Collins and Perras (1991: 34) call it a "shaping force" in Coetsee (1999: 213). The majority of researchers, for example Richards and Engle in Jick, (1993: 83) and Taylor (1994: 71) in Coetsee (1999: 213) tend to stress the motivating or pulling force of visions, as well as the aligning and focusing role of vision statements. The vision should, therefore, reflect the philosophy and specifically the values of the organisation (Jick, 1993: 97).

An effective and well-developed vision statement is characterised by the following: (Kotzé, 2001: 15):

It addresses values as well as performance.

It provides direction to the members of the enterprise, signaling in which direction anticipated future change is headed.

It is symbolic, providing a common frame of reference, identification and commitment.

It is educational, assisting employees to understand the environment and changes in the environment.

It unleashes energy.

It is short; expressed in one or two sentences.

It is expressed as an end result ... a desired destination.

It expresses a dream - an intelligent dream.

It is emotional and motivating, it addresses the heart as well as the mind.

Other characteristics of excellent vision statements are the following:

They should not be too broad or too narrow. Too broad strategic visions convey little meaning or guidance to employees on lower organizations levels. Too narrow visions make it difficult or impossible to generate organizations involvement in interpreting, refining and operationalising the vision (Bartlett \& Ghoshal, 1994: 57-8),

People on all organizations levels should be, as far as practically possible, involved in the development and converting into action of the vision statement (Bartlett \& Ghoshal, 1994: 55); Gratton, 1996: 291; Beer \& Nahria, 2000: 133-34). 
It seems reasonable to conclude then, that an excellent vision statement forms a significant part of an energising organisational purpose that according to Taylor (1994: 71) in Coetsee (1999: 213) gives people's lives and work a semblance of meaning.

\section{CONCLUSION}

In this article, the highly desirable manifestation of aligned commitment was described and a model developed. Successful implementation of all the different aspects of the model and the effective integration of these aspects should contribute significantly to the realisation of the benefits of aligned commitment. These benefits are numerous but might be summarised as follows: "An effectively committed work force will be an innovative, dynamic, competitive and motivated one. Individual self-interest and fragmented departmental/ sectional/unit interests are minimised and people work together to achieve the shared vision" (Myers \& Miller, 1997: 19). This is a desirable option as South African organisations struggle to compete internationally. This brings us full cycle to the strategic plan which was illustrated as being the starting point in the aligned commitment model. The ultimate, successful bottom-line result of a superior strategy formulation and implementation process is the conferring of sustainable competitive advantage on the winning enterprise in its industry. The real benefits come from advantages that competitors cannot easily imitate. To be sustainable, competitive advantage needs to be deeply embedded in the organisation - its human resources, their skills and competencies and the appropriate culture and leadership style.

A key enabler to ensure sustainable competitive advantage is found in the right corporate culture and values, the ability of the organisation and the individual member to learn and change, the strength of the core competencies of the organisation and the willingness of the organisational members to go the extra mile. Additional research efforts can productively be applied in determining the structures, processes, and management styles, most conducive to enabling individual and organisations learning and knowledge management.

A failure to develop and maintain the passionate psychological attachment to organisational vision, values and objectives (aligned commitment) in South African organisations will mean that few will ever become internationally competitive, that sustainable competitive advantage will remain an elusive concept, and that they will have to bear the increased costs associated with more detailed and sophisticated control systems. 


\section{REFERENCES}

1 ANGLE, H.L. \& LAWSON, M.B. (1994) "Organizational Commitment and Employee's Performance Ratings; Both Type of Commitment and Type of Performance Count", Psychological Reports, 75: 1539-51.

2 ARGYRIS, C. (1998) "Empowerment: The Emperor's New Clothes", Harvard Business Review, 76(3).

3 AVERY, C.M. (1999) "All Power to You: Collaborative Leadership Works", The Journal for Quality and Participation, 22(2): 34-6.

4 BARTLETT, C.A. \& GHOSHAL, S. (1994) "Changing the Role of Top Management: Beyond Strategy to Purpose", Harvard Business Review", 72(3).

5 BECKER, T.E., BILLINGS, R.S., EVELETH, D.M. \& GILBERT, N.E. (1996) "Foci and Bases of Employee Commitment: Implications for Job Performance" 39(2): 364-482.

6 BEER, M. \& NOHRIA, N. (2000) "Cracking the Code of Change", Harvard Business Review: 133-41, May-June.

7 BENKHOFF, B. (1996) "Catching Up on Competitors; How Organisations Can Motivate Employees to Work Harder, The International Journal of Human Resource Management, London: Chapman \& Hall.

8 BROWN, J.R., LUSCH, R.F. \& NICHOLSON, C.Y. (1995) "Power and Relationship Commitment: Their Impact on Marketing Channel Member Performance, Journal of Retailing, 71(4): 363-92.

9 BUCHANAN, B. (1974) "Building Organizational Commitment: The Socialisation of Managers in Work Situations", Administrative Science Quarterly, 19(4): 533-46.

10 BYARS, L.L. \& RUE, L.W. (1997) Human Resource Management $\left(5^{\text {th }}\right.$ ed.) Homewood: Irwin.

11 COETSEE, L.D. (1996) "Die Skep van 'n Motiverende Klimaat: 'n Praktiese Gids vir die Suid-Afrikaanse Bestuurder", Potchefstroom: PU vir $\mathrm{CHO}$.

12 ..... (1999) "From Resistance to Commitment", Professional Administrative Quarterly, Summer: 204-22.

13 ..... (2001) "Transformational Leadership (module d) of Strategic Leadership (theme c) of the Strategic Thinking Project", Potchefstroom Business School, PU for CHE.

14 CUMMINGS, T.G. \& WORLEY, C.G. (2001) "Organisation Development and Change" ( $7^{\text {th }}$ ed.) South-Western.

15 DANIEL, E. (1998) "Notes on Power and Dependency", [Web] http:/www.ils.unc.edu/daniel/614/power.html. (date of access: 4 April 2001). 
16 DE COTIS, T.A. \& SUMMERS, T.P. (1987) “A Path Analysis of a Model of the Antecedents and Consequences of Organizational Commitment", Human Relations, 40: 443-70.

17 DYER, W.G. (1997) "Organization Development - As I have Experienced It", Organization Development Journal, 15(2): 27-34.

18 GOODSTEIN, L.D. (1997) "Everything I Really Need to Know: I'm Still Learning" Organization Development Journal, 15(2): 35-42.

19 GRATTON, L. (1996) "Implementing a Strategic Vision - Key Factors for Success, Long Range Planning, 29(3): 290-303.

20 HAMNER, W.E., SCHMIDT, F.L. (1997) Contemporary Problems in Personnel, (revised ed.) Chicago: St. Clair Press.

21 HUGHES, R.L., GINNET, R.C. \& CURPHY, G.J. (1999) "Ch. 11 Charisma and Transformational Leadership", in: Leadership: Enhancing Lessons from Experience, Boston : Irwin/McGraw-Hill: 285-326.

22 JICK, T.D. (1993) Managing Change: Cases and Concepts, Homewood, Illinois: Irwin.

23 KOTTER, J.P. (1985) Power and Influence; Beyond Formal Authority, New York; The Free Press.

24 -..-- (1997) "Power, Dependence and Effective Management", Harvard Business Review, 55(3): 37-47.

25 KOTZé, J.G. (2001) "Integrated Management Systems (Module a) of Strategic Support Systems (Theme b) of the Strategic Thinking Project", Potchefstroom Business School, PU for CHE.

26 -.... (2001) "Organisation Structures (Module c) of Strategic Support Systems (Theme b) of the Strategic Thinking Project", Potchefstroom Business School, PU for CHE.

27 --.- (2001) "Strategic thinking (module a) of Strategic leadership (theme c) of the Strategic Thinking Project", Potchefstroom Business School, PU for CHE.

28 -... (2001) "Formulating Winning Strategies within the New Competitive Paradigm", Alumni Newsletter: Potchefstroom Business School, 1(1), August.

29 KOTZé, J.G. \& COETSEE, L.D. (2001) "The Dynamic Learning Organisation (Module c) of Strategic Leadership (Theme c) of the Strategic Thinking Project", Potchefstroom Business School, PU for CHE.

30 KREITNER, R. \& KINICKI, A. (1995) Organizational Behavior ( $3^{\text {td }}$ ed.) Homewood: Irwin.

31 LAWLER, E.E. III. (1992) The Ultimate Advantage, San Francisco: Jossey-Bass.

32 MATHIEU, J.E. \& ZAJAC, D.M. (1996) "A Review and Meta-Analysis of the Antecedents, Correlates, and Consequences of Organisational Commitment", Psychological bulletin, 108(2): 171-94. 
33 MCKENNA, E. (1994) Business Psychology and Organisational Behaviour, Hove: Lawrence Erlbaum.

34 MEYER, J.P. \& ALLEN, N.J. (1997) Commitment in the Workplace: Theory, Research and Application, London: SAGE.

35 MOWDAY, R.T., PORTER, L.W. \& STEEKS, R.M. (1982) Organizational Linkages: The Psychology of Commitment, Absenteeism and Turnover, San Diego, California: Academic Press.

36 -... (1997) "The Measurement of Organizational Commitment", Journal of Vocational Behaviour: 224-47.

37 MULLINS, L.J. (1996) Management and Organisational Behaviour, London: Pitman Publishing.

38 MYERS, L \& MILLER, K. (1997) "Affective Commitment", People Dynamics, 15(9).

39 O'REILLY, C. III \& CHATMAN, J. (1986) "Organizational Commitment and Psychological Attachment: The Effects of Compliance, Identification and Internalization on Prosocial Behavior", Journal of Applied Psychology, 71(3) 492-99.

40 ROBBINS, S. (1989) Organizational Behavior, New Jersey: PrenticeHall.

41 SCHUITEMA, E. (2001) "The True Meaning of Empowerment. Boardroom", Journal of the Southern African Institute of Chartered Secretaries and Administrators, 2: 24-8.

42 SCHMIDT, W.H. (1997) "Reflections on Groups and O.D", Organization Development Journal, 18(2): 87-90.

43 SIMONS, K. \& DIVILA, A. (1998) "How High is Your Return on Management?" Harvard Business Review: 76(1).

44 SLAGHUIS, L. (2000) "Achievement of Aligned Commitment toward Continuous Improvement Initiatives in the Absence of Direct Line Authority within a Petro-Chemical Company", MBA dissertation, Potchefstroom Business School, PU for CHE.

45 SMIT, P.J. \& CRONJE, G.J. DE J. (eds.) (2000) Management Principles: $A$ Contemporary Edition for Africa $\left(3^{\text {rd }}\right.$ ed.) Kenwyn: Juta.

46 WETLAUFER, S. (1999) "Organising for Empowerment: An Interview with AES's Roger Sant and Dennis Bakke", Harvard Business Review, $77(1)$.

47 WIENER, Y. (1982) "Commitment in Organizations: A Normative View". Academy of Management Review, 7: 418-28.

48 WILSON, P.A. (1995) "The Effects of Politics and Power on the Organizational Commitment of Federal Executives", Journal of Management, 21(1): 101-18.

49 YUKL, G.A. (1981) Leadership in Organizations, Englewood Cliffs, New Jersey: Prentice-Hall. 